Arq. Bras. Med. Vet. Zootec., v.67, n.3, p.707-715, 2015

\title{
Medidas comparativas do padrão morfométrico e perfil energético de éguas Crioulas no terço final da gestação, com diferentes escores corporais
}

\author{
[Comparative measurements of the morphometric pattern and energy profile of Crioula mares \\ in the final third of gestation, with different body condition scores] \\ M.O. Marchiori ${ }^{1}$, S. Kasinger ${ }^{1}$, K.R. Silva ${ }^{2}$, L.S. Souza ${ }^{2}$, L.A. Amaral, \\ C.E.W. Nogueira ${ }^{3}$, V.F.B. Roll ${ }^{3}$
${ }^{1}$ Alunas de pós-graduação - Universidade Federal de Pelotas - Pelotas, RS
${ }^{2}$ Alunos de graduação - Universidade Federal de Pelotas - Pelotas, RS \\ ${ }^{3}$ Universidade Federal de Pelotas - Pelotas, RS
}

\begin{abstract}
RESUMO
O objetivo deste estudo é comparar e descrever medidas morfométricas e perfil energético de éguas da raça Crioula no terço final da gestação. Foram utilizadas vinte éguas gestantes, divididas em 2 grupos conforme o escore corporal (BCS); o GrN ( $\mathrm{n}=10)$, grupo de éguas com BCS 5 ou moderado, e $\mathrm{GrO}(\mathrm{n}=10)$, grupo de éguas obesas ou BCS 9, analisadas conforme o mês de gestação $\left(8^{\circ}, 9^{\circ}, 10^{\circ}\right.$ e $\left.11^{\circ}\right)$. Foram realizadas coletas de sangue e avaliações morfométricas mensais do peso corporal (PC), perímetro torácico (PT), perímetro abdominal (PA), altura da crista do pescoço (AC), espessura de gordura subcutânea na base da cauda (EGBC) e espessura de gordura retroperitoneal (EGRP). Para avaliar o perfil energético, foram mensurados os níveis séricos de triglicerídeos (TAG), ácidos graxos não esterificados (NEFA), Leptina (LEP) e Adiponectina. Os resultados das mensurações analisadas demonstraram no $\mathrm{GrN}$ incremento $(\mathrm{P}<0,05)$ nas variáveis $\mathrm{PC}, \mathrm{PT}$, PA e NEFA do $8^{\circ}$ para o $9^{\circ}$ mês de gestação. Porém, na variável EGBC, o aumento $(\mathrm{P}<0,01)$ foi observado entre o $8^{\circ}$ e o $11^{\circ}$ mês avaliado. No GrO, o PA demonstrou incremento $(\mathrm{P}<0,01)$ entre o $8^{\circ}$ e o $11^{\circ}$ mês de gestação, e a LEP apresentou aumento $(\mathrm{P}<0,05)$ entre o $10^{\circ}$ e o $11^{\circ}$ mês. Quando os dois grupos foram comparados, as variáveis PC, PT, EGBC e EGRP apresentaram diferença $(\mathrm{P}<0,05)$ em todos os meses avaliados. Na análise de correlação, o BCS associou-se com o PC ( $\mathrm{r}=0,691$; $\mathrm{P}<0,0001)$, PT (r=0,705; $\mathrm{P}<0,0001)$, EGBC ( $\mathrm{r}=0,701$; $\mathrm{P}<0,0001)$, EGRP $(\mathrm{r}=0,627 ; \mathrm{P}<0,0001)$, níveis séricos de LEP $(\mathrm{r}=0,426 ; \mathrm{P}<0,0001)$ e Adiponectina $(\mathrm{r}=0,217$; $\mathrm{P}<0,05)$. Dessa forma, pode-se afirmar que a gordura corporal aumentou progressivamente nas éguas do GrN, diferentemente do observado no GrO. Através dos métodos utilizados neste trabalho, torna-se possível a avaliação prática da morfometria das éguas da raça Crioula no terço final da gestação, possibilitando de forma objetiva a identificação de indivíduos obesos.
\end{abstract}

Palavras-chave: morfometria, gestação, raça Crioula, obesidade

\begin{abstract}
The aim of this study was to compare and describe morphometric measurements and energy profile of the Crioula breed mares at the end of gestation. Twenty pregnant mares were used and separated into 2 groups according to body condition score $(B C S)$. The GrN $(n=10)$ group of mares with BCS 5 or moderate and GrO $(n=10)$ group of obese mares or BCS 9 were analyzed according to the month of pregnancy (8th, 9th, 10th and 11th). Blood samples and monthly morphometric evaluation were performed for body weight (PC), heart girth $(P T)$, waist circumference (PA), height of the crest of the neck (AC), thickness subcutaneous fat on the base of the tail (EGBC) and retroperitoneal (EGRP). To evaluate the energy profile serum levels of triglycerides (TAG), non-esterified fatty acids (NEFA), leptin (LEP) and adiponectin were measured. The results of the analyzed measurements showed an increase in $G r N(P<0.05)$ in the PC, PT, PA and NEFA variables between the 8th and 9th month of pregnancy. Although there was an increase $(P<0.01)$ between the 8th and 11th month of pregnancy in the EGBC variable, in GrO the PA was increased $(P<0.01)$ between the 8 th and 11th month of pregnancy and the LEP showed an increase $(P<0.05)$ between the 10th and 11th month. When both groups were compared, the variables $P C, P T, E G B C$ and EGRP showed differences $(P<0.05)$ in all
\end{abstract}

Recebido em 27 de maio de 2014

Aceito em 24 de fevereiro de 2015

E-mail: millieve@yahoo.com.br 
months evaluated. In the correlation the BCS was associated with $P C(r=0.691, P<0.0001), P T(r=0.705$, $P<0.0001), E G B C(r=0.701, P<0.0001), E G R P(r=0.627, P<0.0001)$, serum leptin levels $(r=0.426$, $P<0.0001)$ and adiponectin $(r=0.217, P<0.05)$. Thus, it can be stated that the body fat increased progressively in mares GrN, different from that observed in GrO. Therefore, by the methods used in this study, the morphometry practical evaluation of the Crioula breed mares in the last third of gestation became possible, allowing an objective way to identify obese individuals.

Keywords: morphometry, pregnancy, Crioula breed, obesity

\section{INTRODUÇÃO}

A indústria do cavalo Crioulo vem crescendo rapidamente em todo o território nacional. Somente no ano de 2013, foram registrados 27.753 novos animais na raça. A atividade envolve grandes investimentos, movimentando o mercado nacional e internacional (Anuário..., 2013).

Com a finalidade de produzir animais cada vez mais competitivos morfologicamente, foram introduzidas alterações na dieta e no manejo de criação. $O$ confinamento e o excesso de alimentos energéticos proporcionam um maior acúmulo de gordura e consequentemente uma aparência externa mais arredondada, tornando o animal esteticamente mais bonito (Paz et al., 2013). Esse padrão alimentar acabou por se estender também a potros e éguas em reprodução, tornando os indivíduos predispostos a desencadear distúrbios metabólicos e obesidade. Tais modificações no manejo também foram observadas e descritas por Scheibe e Streich (2003) em outras raças. Segundo esses autores, a domesticação dos cavalos, aliada ao confinamento e ao excesso de fornecimento de alimentos ricos em energia, são os responsáveis pelo aumento no índice da obesidade em equinos.

$\mathrm{Na}$ raça Crioula não há estudos sobre a morfometria e o perfil energético durante a gestação, período marcado por diversas alterações metabólicas. Dessa forma, torna-se importante estudar o padrão biométrico e alguns marcadores do perfil energético, a fim de entender como tais alterações no manejo de criação estão influenciando o metabolismo das éguas dessa raça no terço final da gestação.

Medidas corporais maternas são usadas em humanos durante a gestação como método de acompanhamento do desenvolvimento fetal
(Martinelli et al., 2002) e ganho de peso da própria gestante (Castellano Filho et al., 2012). $\mathrm{O}$ monitoramento nutricional de éguas gestantes, através de uma escala do escore corporal (BCS) e de medidas objetivas, como a mensuração ultrassonográfica e a altura da crista do pescoço, são algumas formas de identificar animais obesos, que possam apresentar distúrbios metabólicos, gerando alterações que predisponham a modificações no metabolismo fetal (Carter et al., 2009).

Para auxiliar na identificação do BCS, medida subjetiva descrita por Henneke et al. (1983), e identificar alterações sutis no padrão de gordura corporal, técnicas objetivas, como a ultrassonografia e a adiposidade da crista do pescoço podem ser utilizadas (Gentry et al., 2004; Carter et al., 2009). Segundo Dugdale et al. (2011), a avaliação morfométrica e a identificação do BCS torna-se mais difícil em animais obesos, devido às variações sutis nas reservas de gordura; por isso faz-se necessário aliar as medidas subjetivas a medidas objetivas e ao perfil energético, no intuito de identificar indivíduos susceptíveis a alterações metabólicas.

O perfil bioquímico foi estudado por Takahiro e Mitsuo (2011), em éguas de tração gestantes, através da avaliação de alguns marcadores do perfil energético, tais como os ácidos graxos não esterificados (NEFA), colesterol e triglicerídeos (TAG). Kearns et al. (2006), analisando alguns marcadores de adiposidade em equinos, observaram que a obesidade estava associada com maiores concentrações plasmáticas de Leptina e menores concentrações plasmáticas de Adiponectina.

O objetivo deste estudo é comparar e descrever o padrão morfométrico e o perfil energético de éguas Crioulas, com diferentes escores corporais, no terço final da gestação. 


\section{MATERIAL E MÉTODOS}

Este projeto foi aprovado pela Comissão de Ética em Experimentação Animal, estando cadastrado sob o número CEEA 6058.

Para o estudo, foram utilizadas 80 observações, oriundas de 20 éguas hígidas, da raça Crioula, no terço final de gestação $\left(8^{\circ}, 9^{\circ}, 10^{\circ}\right.$ e $11^{\circ}$ mês $)$. As éguas possuíam idades que variavam de 8 a 14 anos, com altura corporal média de $1,41 \mathrm{~cm}$. Os animais estavam alojados em uma mesma propriedade, no município de Pelotas-RS, estando submetidas a um mesmo manejo sanitário.

As éguas foram categorizadas de acordo com o período gestacional e avaliadas conforme uma escala de escore corporal (BCS) em que se encontravam no momento da coleta de dados. O período gestacional foi estabelecido pela data da ovulação e confirmado pela dimensão da órbita fetal. O escore corporal foi avaliado subjetivamente por um mesmo observador, treinado através do sistema originalmente descrito por Henneke et al. (1983), modificado por Kohnke et al. (1992), que inclui uma escala de 9 pontos, sendo o BCS 1 (muito magro) e o BCS 9 (extremamente gordo). O sistema BCS, segundo Kohnke et al. (1992), consiste na análise tátil e visual de seis regiões anatômicas do corpo (pescoço, cernelha, lombo, base da cauda, costelas, ombro). Para cada região corporal, é definida uma nota e, através da média das seis pontuações, chega-se ao resultado final.

As éguas que apresentavam escore corporal 5 foram consideradas integrantes do grupo controle GrN ( $\mathrm{n}=10)$, classificadas como animais com escore corporal moderado, e as que apresentavam escore corporal 9 foram incluídas no $\mathrm{GrO}(\mathrm{n}=10)$, grupo dos animais obesos.

O manejo nutricional dos animais dentro da propriedade era distinto. Os animais do $\mathrm{GrN}$ estavam em campo nativo melhorado com pastagem cultivada com azevém (Lolium multiflorum), o GrO estava em um potreiro com pastagem cultivada com azevém (Lolium multiflorum), cornichão (Lotus corniculatus) e trevo branco (Trifolium repens).

A coleta dos dados morfométricos ocorreu durante os meses de setembro a dezembro de 2012, mensalmente, no período matinal. Dentro de cada período gestacional, foram realizadas mensurações visuais do escore corporal e aferições objetivas de alguns parâmetros morfométricos dos animais. Além dessas medidas, foram coletadas amostras sanguíneas para avaliação metabólica.

O peso das éguas no terço final da gestação foi estimado através da fita-peso padrão da marca Suprivet ${ }^{\circledR}$ (Suprivet, Brasil), disponível comercialmente para espécie equina. Foi realizada também a mensuração com fita métrica dos perímetros de circunferência torácica na região do esterno, após expiração, além da circunferência no $12^{\circ}$ espaço intercostal (Carroll e Huntington, 1988).

A gordura subcutânea foi medida através de um aparelho ultrassonográfico da marca SIUI, com frequência de $5.0 \mathrm{MHz}$ e sonda linear. Foram realizadas as medidas na região da base da cauda, especificamente $7,6 \mathrm{~cm}$ cranial a base da cauda e $5 \mathrm{~cm}$ lateral, com a sonda posicionada transversalmente à linha média (Gentry et al., 2004). Além dessa medida, foi avaliada também a gordura ventroabdominal retroperitoneal na porção imediatamente caudal ao apêndice xifoide, lateral à linha média, com a sonda numa posição paralela à linha média ventral, conforme descrito por Dugdale et al. (2011).

As estimativas de depósito de gordura na região da crista do pescoço foram obtidas através da identificação do ligamento nucal, o qual serviu como limite ventral da medida. A altura da crista do pescoço foi medida na porção média do comprimento total do pescoço (medida aferida da base da orelha até a porção mais alta da cernelha), estando este em posição relaxada a um ângulo de aproximadamente $45^{\circ}$. Estabelecida a porção média, o ligamento nucal é localizado com o auxílio de um aparelho ultrassonográfico, com frequência de 5.0MHZ e sonda linear, e uma fita métrica é posicionada dorsalmente ao ligamento nucal até a porção final do pescoço, que pode ser palpada ou visualmente identificada (Carter et al., 2009).

Juntamente com as medidas biométricas, foi analisado o perfil energético através das análises de Triacilglicerídeos (TAG), Ácidos Graxos Não Esterificados (NEFA), Leptina e Adiponectina. 
Para as análises laboratoriais, foram coletadas amostras de $15 \mathrm{~mL}$ de sangue, através de punção externa da veia jugular, utilizando sistema de tubos estéreis Vacutainer®. Posteriormente, as amostras foram centrifugadas a $3.200 \mathrm{~g}$ durante 10 minutos para separação do soro, o qual foi armazenado congelado a $-20^{\circ} \mathrm{C}$. A análise laboratorial foi realizada no laboratório de bioquímica da UFPel, onde foram avaliadas as concentrações de triacilglicerídeos (Triglicerides ( - Labtest Diagnóstica S.A, Brasil) e NEFA (Enzychrom Free Fatty Acid Assay Kit® Bioassay Systems - EUA), pelo método enzimático e leitura por colorimetria, modificado por Baumann (1986), citado por Johnson e Peters (1993). A Leptina (Kit for Leptina (LEP) ® Uscn life science Inc - EUA) e Adiponectina (Human Adiponectin ELISA Kit ${ }^{\circledR}$ - EMD Millipore Corporation - USA) foram realizadas através da técnica Enzyme - Linked Immunosorbent Assay (ELISA).

Para análise estatística dos dados, foi utilizado o programa STATISTIX $® \quad$ (2003). O teste Shapiro-Wilk foi realizado a fim de verificar se as variáveis estavam dentro da normalidade. Para o estudo, foi utilizada uma significância estatística com $\mathrm{P}<0.05$.

Foi realizada a estatística descritiva de todas as variáveis conforme a distribuição dos grupos. Para verificar a diferença entre as médias amostrais das variáveis analisadas em cada grupo (GrN e GrO) separadamente e comparar os dados do GrN versus $\mathrm{GrO}$ em cada mês de gestação, foram realizados a Análise de Variância para testes paramétricos ANOVA, utilizando o Teste de Tukey, e o Teste de kruskal-wallis, para os dados não paramétricos.

A correlação foi realizada através do Teste Linear de Pearson a fim de estimar a força de associação entre as variáveis. $\mathrm{O}$ mês de gestação e o escore corporal foram correlacionados com as variáveis morfométricas. Para avaliar a força de interação entre as variáveis morfométricas e o perfil energético, foi utilizado o Coeficiente de Correlação de Spearman, prova não paramétrica.

\section{RESULTADOS}

Os resultados das mensurações morfométricas demonstraram que os incrementos observados foram mais expressivos $(\mathrm{P}<0,05)$ nas éguas de escore corporal normal $(\mathrm{GrN})$.

O ganho de peso ocorreu de forma linear no decorrer dos meses de gestação no $\mathrm{GrN}$, havendo um aumento de $33,5 \mathrm{~kg}(\mathrm{P}<0,05)$ do $8^{\circ}$ ao $11^{\circ}$ mês. As variáveis perímetro torácico $(\mathrm{P}<0,05)$ e circunferência do perímetro abdominal $(\mathrm{P}<0,05)$ demonstraram incremento do $8^{\circ}$ para o $9^{\circ}$ mês de gestação, havendo uma tendência $(\mathrm{P}>0,05)$ crescente até o último mês avaliado. No entanto, o GrO apresentou incremento $(\mathrm{P}<0,01)$ apenas no perímetro abdominal $(19 \mathrm{~cm})$, entre o $8^{\circ}$ e o $11^{\circ}$ mês de gestação, como pode ser observado na Tabela 1 .

Tabela 1. Valores médios ( \pm erro padrão da média) dos grupos controle $(\mathrm{GrN})$ e $\mathrm{GrO}$ das variáveis peso corporal (PC), perímetro torácico (PT) e perímetro abdominal (PA) durante o $8^{\circ}, 9^{\circ}, 10^{\circ}$ e $11^{\circ}$ mês de gestação de éguas da raça Crioula

\begin{tabular}{cccccc}
\hline $\mathrm{GR}$ & $\mathrm{MG}$ & $\mathrm{N}$ & $\mathrm{PC}(\mathrm{Kg})$ & $\mathrm{PT}(\mathrm{m})$ & $\mathrm{PA}(\mathrm{m})$ \\
\hline $\mathrm{GrN}$ & $8^{\mathrm{o}}$ & 10 & $436.50 \pm 7.23 \mathrm{aA}$ & $1.75 \pm 0.01 \mathrm{aA}$ & $2.06 \pm 0.02 \mathrm{aA}$ \\
$\mathrm{GrO}$ & $8^{\circ}$ & 10 & $511.50 \pm 22.85 \mathrm{yB}$ & $1.86 \pm 0.02 \mathrm{yB}$ & $2.11 \pm 0.03 \mathrm{yA}$ \\
$\mathrm{GrN}$ & $9^{\mathrm{o}}$ & 10 & $463.22 \pm 6.49 \mathrm{bA}$ & $1.79 \pm 0.008 \mathrm{bA}$ & $2.17 \pm 0.02 \mathrm{bA}$ \\
$\mathrm{GrO}$ & $9^{\circ}$ & 10 & $517 \pm 11.69 \mathrm{yB}$ & $1.87 \pm 0.01 \mathrm{yB}$ & $2.20 \pm 0.03 \mathrm{yzA}$ \\
$\mathrm{GrN}$ & $10^{\circ}$ & 10 & $468.75 \pm 1.25 \mathrm{bA}$ & $1.81 \pm 0.00 \mathrm{bA}$ & $2.22 \pm 0.05 \mathrm{bA}$ \\
$\mathrm{GrO}$ & $10^{\circ}$ & 10 & $527.20 \pm 7.96 \mathrm{yB}$ & $1.89 \pm 0.01 \mathrm{yB}$ & $2.24 \pm 0.01 \mathrm{yzA}$ \\
$\mathrm{GrN}$ & $11^{\mathrm{o}}$ & 10 & $470.00 \pm 8.51 \mathrm{bA}$ & $1.83 \pm 0.01 \mathrm{bA}$ & $2.24 \pm 0.03 \mathrm{bA}$ \\
$\mathrm{GrO}$ & $11^{\mathrm{o}}$ & 10 & $533.59 \pm 10.75 \mathrm{yB}$ & $1.92 \pm 0.02 \mathrm{yB}$ & $2.30 \pm 0.02 \mathrm{zA}$ \\
\hline
\end{tabular}

Médias seguidas por letras minúsculas diferentes na mesma coluna diferem estatisticamente $(\mathrm{P}<0,05)$ na comparação dos resultados do grupo GrN nos meses de gestação. Médias seguidas por letras minúsculas (y e z) diferentes na mesma coluna diferem estatisticamente $(\mathrm{P}<0,05)$ na comparação dos dados do grupo GrO nos meses de gestação. Médias seguidas por letras maiúsculas diferentes na mesma coluna diferem estatisticamente $(\mathrm{P}<0,05)$ na comparação dos grupos $\mathrm{GrN}$ versus $\mathrm{GrO}$ em cada mês de gestação avaliado.

GR: Grupos observados no estudo; GrN: Grupo controle ou de éguas com BCS 5; GrO: Grupo de éguas obesas ou com BCS 9; MG: Mês de Gestação; N: Número de éguas; PC: Peso Corporal; PT: Perímetro Torácico; PA: Perímetro Abdominal. 
Nas avaliações específicas de adiposidade, apenas no $\mathrm{GrN}$ houve incremento $(\mathrm{P}<0,01)$ da variável EGBC do $8^{\circ}$ para o $11^{\circ}$ mês de gestação (Tab. 2).

Com os resultados obtidos no estudo, percebe-se que existe uma diferença nos dados morfométricos de éguas gestantes normais e obesas. Todas as variáveis analisadas diferiram $(\mathrm{P}<0,05)$ quando os grupos de éguas normais e obesas foram comparados em cada mês de gestação, as excessões foram as variáveis perímetro abdominal e a altura da crista do pescoço no $11^{\circ}$ mês de gestação $(\mathrm{P}=0,07)$ (Tab. 2).

Tabela 2. Valores médios ( \pm erro padrão da média) dos grupos controle $(\mathrm{GrN})$ e GrO das variáveis altura da crista do pescoço (AC), espessura de gordura subcutânea na base da cauda (EGBC) e espessura de gordura retroperitoneal (EGRP) durante os meses de gestação avaliados em éguas da raça Crioula

\begin{tabular}{cccccc}
\hline $\mathrm{GR}$ & $\mathrm{MG}$ & $\mathrm{N}$ & $\mathrm{AC}(\mathrm{cm})$ & $\mathrm{EGBC}(\mathrm{cm})$ & EGRP $(\mathrm{cm})$ \\
\hline $\mathrm{GrN}$ & 8 & 10 & $4.25 \pm 0.28 \mathrm{aA}$ & $0.68 \pm 0.19 \mathrm{aA}$ & $0.81 \pm 0.73 \mathrm{aA}$ \\
$\mathrm{GrO}$ & 8 & 10 & $5.87 \pm 0.65 \mathrm{yB}$ & $1.917 \pm 0.35 \mathrm{yB}$ & $1.59 \pm 0.12 \mathrm{yB}$ \\
$\mathrm{GrN}$ & 9 & 10 & $5.0 \pm 0.25 \mathrm{aA}$ & $0.824 \pm 0.10 \mathrm{abA}$ & $0.85 \pm 0.80 \mathrm{aA}$ \\
$\mathrm{GrO}$ & 9 & 10 & $6.58 \pm 0.80 \mathrm{yB}$ & $1.600 \pm 0.15 \mathrm{yB}$ & $1.56 \pm 0.09 \mathrm{yB}$ \\
$\mathrm{GrN}$ & 10 & 10 & $4.87 \pm 0.71 \mathrm{aA}$ & $0.89 \pm 0.18 \mathrm{abA}$ & $0.95 \pm 0.17 \mathrm{aA}$ \\
$\mathrm{GrO}$ & 10 & 10 & $6.93 \pm 0.29 \mathrm{yB}$ & $1.737 \pm 0.08 \mathrm{yB}$ & $1.90 \pm 0.12 \mathrm{yB}$ \\
$\mathrm{GrN}$ & 11 & 10 & $5.5 \pm 0.53 \mathrm{aA}$ & $1.22 \pm 0.13 \mathrm{bA}$ & $1.13 \pm 0.03 \mathrm{aA}$ \\
$\mathrm{GrO}$ & 11 & 10 & $6.72 \pm 0.28 \mathrm{yA}$ & $1.843 \pm 0.09 \mathrm{yB}$ & $2.08 \pm 0.12 \mathrm{yB}$ \\
\hline
\end{tabular}

Médias seguidas por letras minúsculas diferentes na mesma coluna diferem estatisticamente $(\mathrm{P}<0,05)$ na comparação dos resultados do grupo GrN nos meses de gestação. Médias seguidas por letras minúsculas (y e z) diferentes na mesma coluna diferem estatisticamente $(\mathrm{P}<0,05)$ na comparação dos dados do grupo GrO nos meses de gestação. Médias seguidas por letras maiúsculas diferentes na mesma coluna diferem estatisticamente $(\mathrm{P}<0,05)$ na comparação dos grupos $\mathrm{GrN}$ versus $\mathrm{GrO}$ em cada mês de gestação avaliado.

GR: Grupos observados no estudo; GrN: Grupo controle ou de éguas com BCS 5; GrO: Grupo de éguas obesas com BCS 9; MG: Mês de Gestação; N: Número de éguas; AC: Altura da Crista do Pescoço; EGBC: Espessura de gordura subcutânea na base da cauda; EGRP: Espessura de gordura retroperitoneal.

$\mathrm{Na}$ avaliação do perfil energético do grupo controle $(\mathrm{GrN})$, pode-se perceber que os níveis séricos de NEFA diminuíram $(\mathrm{P}<0,01)$ entre o $8^{\circ}$ e o $9^{\circ}$ mês avaliado. No GrO pode-se observar um incremento $(\mathrm{P}<0,05)$ nos níveis séricos de Leptina entre o $10^{\circ}$ e $11^{\circ}$ mês de gestação. As demais variáveis não apresentaram variações. Quando os dados referentes ao perfil energético foram analisados nos meses de gestação e os grupos ( $\mathrm{GrN}$ versus $\mathrm{GrO}$ ) foram comparados, apenas os níveis séricos de Leptina no último mês de gestação diferiram $(\mathrm{P}<0,001)$ (Tab. 3).

Na Análise de Correlação de Pearson, percebe-se maior interação do mês de gestação com a circunferência do perímetro abdominal medido no $12^{\circ}$ espaço intercostal $(r=0,544 ; \mathrm{P}<0,0001)$. $\mathrm{O}$ escore corporal apresentou forte associação com as variáveis morfométricas $\mathrm{PC} \quad(\mathrm{r}=0,691$; $\mathrm{P}<0,0001)$, PT $\quad(\mathrm{r}=0,705 ; \mathrm{P}<0,0001)$, EGBC $(\mathrm{r}=0,701 ; \quad \mathrm{P}<0,0001) \quad$ e $\quad$ EGRP $\quad(\mathrm{r}=0,627$; $\mathrm{P}<0,0001)$.

$\mathrm{Na}$ Correlação de Spearman, a Leptina foi a variável metabólica que melhor se correlacionou com o BCS $(\mathrm{r}=0,426 ; \quad \mathrm{P}<0,0001)$, EGBC $(\mathrm{r}=0,418 ; \quad \mathrm{P}<0,0001) \quad$ e $\quad$ EGRP $\quad(\mathrm{r}=0,313$; $\mathrm{P}<0,0001)$. O NEFA se correlacionou negativamente com o mês de gestação ( $\mathrm{r}=0,311$; $\mathrm{P}=0,02), \quad \mathrm{PC} \quad(\mathrm{r}=0,472 ; \quad \mathrm{P}=0,0005) \quad$ e $\mathrm{AC}$ ( $\mathrm{r}=0,391 ; \mathrm{P}=0,004)$. O TAG se correlacionou positivamente com o NEFA $(\mathrm{R}=0,263 ; \mathrm{P}=0,05) \mathrm{e}$ Leptina $(r=0,490 ; \quad P=0,0003)$. A Leptina e a Adiponectina se correlacionaram positivamente $(\mathrm{r}=0,461 ; \mathrm{P}=0,0006)$. 


\section{Marchiori et al.}

Tabela 3. Média ( \pm erro padrão) dos grupos controle $(\mathrm{GrN})$ e $\mathrm{GrO}$ referente a níveis séricos de Triacilglicerídeos (TAG), Ácidos Graxos Não Esterificados (NEFA), Leptina e Adiponectina no decorrer dos meses de gestação avaliados em éguas da raça Crioula

\begin{tabular}{ccccccc}
\hline GR & MG & N & $\begin{array}{c}\text { TAG } \\
(\mathrm{mmol} / \mathrm{L})\end{array}$ & $\begin{array}{c}\text { NEFA } \\
(\mathrm{mmol} / \mathrm{L})\end{array}$ & $\begin{array}{c}\text { Leptina } \\
(\mathrm{ng} / \mathrm{mL})\end{array}$ & $\begin{array}{c}\text { Adiponectina } \\
(\mathrm{ng} / \mathrm{mL})\end{array}$ \\
\hline $\mathrm{GrN}$ & 8 & 10 & $2.14 \pm 0.34 \mathrm{aA}$ & $0.36 \pm 0.05 \mathrm{aA}$ & $0.29 \pm 0.26 \mathrm{aA}$ & $0.12 \pm 0.09 \mathrm{aA}$ \\
$\mathrm{GrO}$ & 8 & 10 & $1.50 \pm 0.23 \mathrm{yA}$ & $0.20 \pm 0.11 \mathrm{yA}$ & $0.69 \pm 0.54 \mathrm{yA}$ & $0.16 \pm 0.14 \mathrm{yA}$ \\
$\mathrm{GrN}$ & 9 & 10 & $1.32 \pm 0.14 \mathrm{aA}$ & $0.07 \pm 0.02 \mathrm{bA}$ & $0.44 \pm 0.39 \mathrm{aA}$ & $0.09 \pm 0.05 \mathrm{aA}$ \\
$\mathrm{GrO}$ & 9 & 10 & $1.52 \pm 0.27 \mathrm{yA}$ & $0.03 \pm 0.01 \mathrm{yA}$ & $1.55 \pm 0.78 \mathrm{yA}$ & $0.13 \pm 0.04 \mathrm{yA}$ \\
$\mathrm{GrN}$ & 10 & 10 & $1.30 \pm 0.32 \mathrm{aA}$ & $0.09 \pm 0.07 \mathrm{bA}$ & $0.43 \pm 0.39 \mathrm{aA}$ & $0.15 \pm 0.08 \mathrm{aA}$ \\
$\mathrm{GrO}$ & 10 & 10 & $1.76 \pm 0.34 \mathrm{yA}$ & $0.09 \pm 0.02 \mathrm{yA}$ & $2.54 \pm 1.30 \mathrm{yA}$ & $0.24 \pm 0.10 \mathrm{yA}$ \\
$\mathrm{GrN}$ & 11 & 10 & $2.37 \pm 0.09 \mathrm{aA}$ & $0.14 \pm 0.10 \mathrm{abA}$ & $0.29 \pm 0.12 \mathrm{aB}$ & $0.02 \pm 0.00 \mathrm{aA}$ \\
$\mathrm{GrO}$ & 11 & 10 & $2.45 \pm 0.60 \mathrm{yA}$ & $0.17 \pm 0.06 \mathrm{yA}$ & $6.22 \pm 1.44 \mathrm{zC}$ & $0.50 \pm 0.48 \mathrm{yA}$ \\
\hline
\end{tabular}

Médias seguidas por letras minúsculas diferentes na mesma coluna diferem estatisticamente $(\mathrm{P}<0,05)$ na comparação dos resultados do grupo GrN nos meses de gestação. Médias seguidas por letras minúsculas (y e z) diferentes na mesma coluna diferem estatisticamente $(\mathrm{P}<0,05)$ na comparação dos dados do grupo GrO nos meses de gestação. Médias seguidas por letras maiúsculas diferentes na mesma coluna diferem estatisticamente $(\mathrm{P}<0,05)$ na comparação dos grupos $\mathrm{GrN}$ versus $\mathrm{GrO}$ em cada mês de gestação avaliado.

GR: Grupos observados no estudo; GrN: Grupo controle ou de éguas com BCS 5; GrO: Grupo de éguas obesas ou com BCS 9; MG: Mês de gestação; N: Número de Animais; TAG: Triacilglicerídeos; NEFA: Ácidos Graxos Não Esterificados.

\section{DISCUSSÃO}

As medidas morfométricas obtidas neste estudo podem ser um referencial para a mensuração do perfil metabólico e energético de éguas Crioulas gestantes. Os resultados demonstram que há uma diferença $(\mathrm{P}<0,05)$ no último trimestre da gestação entre as médias de ganho de peso corporal das éguas da raça Crioula normais $(\mathrm{GrN})$ e obesas (GrO). O menor ganho de peso nos indivíduos obesos durante o último trimestre da gestação também foi observado por Knight et al. (2009), estudando mulheres grávidas com sinais de obesidade.

O perímetro torácico aumentou do $8^{\circ}$ para o $9^{\circ}$ mês de gestação nos animais do GrN; no entanto, nos animais obesos, tal variável não apresentou alterações. Tais resultados corroboram os encontrados por Dugdale et al. (2011), que avaliaram o padrão morfométrico em pôneis e verificaram que o perímetro torácico aumentava nos pôneis não obesos, mas se mantinha constante nos pôneis obesos.

A mensuração da circunferência do perímetro abdominal no $12^{\circ}$ espaço intercostal apresentou crescimento $(\mathrm{P}<0,05)$ apenas no $\mathrm{GrN}$ do $8^{\circ}$ para o $9^{\circ}$ mês de gestação. Na Análise de Correlação de Pearson, quando as variáveis morfométricas foram associadas com a evolução dos meses de gestação, houve maior correlação do mês de gestação com a circunferência do perímetro abdominal $(\mathrm{r}=0,544 ; \mathrm{P}<0,0001)$. Tal resultado pode ser justificado pelo fato de que, durante o último trimestre de gestação, devido ao desenvolvimento e ganho de peso fetal, o abdômen é a região anatômica que mais apresenta alteração morfológica, aumentando seu tamanho, conforme foi descrito por Meyer e Ahlswede (1978).

Quando os grupos ( $\mathrm{GrN}$ e $\mathrm{GrO}$ ) foram avaliados separadamente, a espessura de gordura retroperitoneal e a altura da crista do pescoço não demonstraram variação ao longo dos meses observados. No entanto, quando os grupos foram comparados ( $\mathrm{GrN}$ versus $\mathrm{GrO}$ ), houve diferença $(\mathrm{P}<0,05)$ em todos os meses observados, exceto na variável $\mathrm{AC}$ no $11^{\circ}$ mês de gestação $(\mathrm{P}>0,05)$. Dugdale et al. (2011), em um estudo com pôneis obesos e não obesos, os quais foram submetidos a uma dieta que favorecia o incremento do BCS, observaram que a espessura de gordura retroperitoneal e a altura da crista do pescoço apresentavam maior incremento nos pôneis não obesos, quando ambos os grupos eram comparados.

Entretanto, em nosso estudo com animais da raça Crioula, não foi observado incremento nas variáveis espessura de gordura retroperitoneal e altura da crista do pescoço no decorrer dos meses de gestação avaliados. Apesar de as éguas do 
GrN terem apresentado um incremento no peso corporal, elas mantiveram-se durante todo o estudo dentro de um padrão corporal de normalidade, podendo justificar dessa forma o resultado encontrado.

A variável espessura de gordura subcutânea na base da cauda revelou nas éguas do $\mathrm{GrN}$ um incremento $(\mathrm{P}<0,01)$ do $8^{\circ}$ para o $11^{\circ}$ mês de gestação. Tal resultado não foi observado nas éguas do GrO. Lawrence et al. (1992), observando o comportamento dessa variável em éguas gestantes da raça Quarto de Milha, de padrão corporal normal, perceberam um pico máximo na espessura de gordura subcutânea na base da cauda aproximadamente aos 225 dias de gestação, havendo uma tendência decrescente $(\mathrm{P}>0,05)$ nessa variável no $10^{\circ}$ e $11^{\circ}$ mês de gestação. Os resultados encontrados sugerem que as éguas da raça Quarto de Milha ganham peso no terço final da gestação, acumulando suas reservas de energia para posteriormente serem utilizadas durante a lactação.

Bender et al. (2014), no entanto, afirmam que, nas éguas gestantes, à medida que elas se aproximam do parto, a pele e a musculatura da região dorsolombar, bem como a base da cauda, se distendem, diminuindo a cobertura de gordura nessas áreas; portanto, devendo-se avaliar os depósitos de gordura atrás das escápulas e no pescoço.

Manso Filho et al. (2009) determinaram a porcentagem de gordura corporal (PG) em 121 equinos de diferentes categorias e raças, criados num regime intensivo na região do Recife (PE), através de avaliações ultrassonográficas da garupa. Puderam, através desse estudo, concluir que, nas éguas gestantes, não havia diferença $(\mathrm{P}>0,05)$ na $\mathrm{PG}$ entre os dois terços iniciais e o terço final da gestação. A divergência dos resultados encontrados pode estar relacionada ao fato de Manso Filho et al. (2009) terem utilizado variáveis (raça dos animais, alimentação e região) distintas das utilizadas em nosso estudo.

Os níveis de triglicerídeos mantiveram-se inalterados durante o decorrer dos meses de gestação em ambos os grupos, mantendo-se dentro do padrão de referência $(0-1.0 \mathrm{mmol} / \mathrm{L})$. Esse resultado é similar ao encontrado por Takahiro e Mitsuo (2011), que não observaram alterações nas concentrações de triglicerídeos em éguas de tração nas duas semanas que antecederam o parto.

No GrN, os níveis de NEFA apresentaram uma diminuição significativa $(\mathrm{P}<0,01)$ do $8^{\circ}$ para o $9^{\circ}$ mês de gestação; havendo uma discreta $(\mathrm{P}>0,05)$ elevação nos níveis de NEFA no último mês. No entanto, todos os valores encontrados mantiveram-se dentro dos níveis fisiológicos, que estão entre 0.00 a $0.46 \mathrm{mmol} / \mathrm{L}$, segundo Dugdale et al. (2011). Takahiro e Mitsuo (2011) também não encontraram alterações significativas nas concentrações de NEFA no pré-parto de éguas de tração (Heavy Draft Horse). Quando os grupos $\mathrm{GrN}$ e GrO foram comparados, não houve diferença nos níveis de NEFA nos meses avaliados. Esses dados vêm de encontro aos observados por Dugdale et al. (2011), os quais perceberam que apesar das concentrações médias de NEFA nos grupos de animais obesos e não obesos permanecerem constantes e dentro da faixa de referência de laboratório, os pôneis obesos apresentavam valores maiores $(\mathrm{P}<0,0001)$ nos níveis de NEFA do que os pôneis não obesos.

Os níveis de Leptina, nas éguas da raça Crioula, no $\mathrm{GrN}$, não diferiram entre os meses de gestação avaliados; já no $\mathrm{GrO}$, foi observado um aumento nos níveis de Leptina do $10^{\circ}$ para o $11^{\circ}$ mês de gestação. Fradinho et al. (2014) observaram um aumento $(\mathrm{P}<0,05)$ nas concentrações de Leptina concomitante ao incremento do BCS, do $9^{\circ}$ ao $11^{\circ}$ mês de gestação, em éguas da raça Lusitano.

O BCS, em nosso estudo, demonstrou correlação positiva com as variáveis morfométricas PC ( $\mathrm{r}=0,691 ; \mathrm{P}<0,0001)$, PT $(\mathrm{r}=0,705 ; \mathrm{P}<0,0001)$, EGBC $(\mathrm{r}=0,701 ; \mathrm{P}<0,0001)$, EGRP $\quad(\mathrm{r}=0,627$; $\mathrm{P}<0,0001)$ e com os níveis séricos de Leptina $(\mathrm{r}=0,426 ; \mathrm{P}<0,0001)$ e Adiponectina $(\mathrm{r}=0,217$; $\mathrm{P}<0,05)$. Esses resultados corroboram as observações realizadas por Carrol e Huntington (1988), os quais observaram que a altura, quando é semelhante entre animais de um mesmo plantel, o peso tem alta correlação $(r=0,70$; $\mathrm{P}<0,001)$ com a condição corporal.

A associação positiva entre Leptina e o BCS no terço final da gestação também foi observada por Fradinho et al. (2014) em éguas da raça Lusitano. Cavinder et al. (2007) observaram que animais que possuem maior quantidade de 
gordura corporal armazenada apresentam maiores níveis de Leptina. Kearns (2006) avaliaram as concentrações plasmáticas de Adiponectina e Leptina em 23 éguas maduras (idade: $10 \pm 3$ anos) para testar a hipótese de que adipocitocinas eram proporcionais à adiposidade em cavalos. Segundo o autor, a Adiponectina variava conforme as modificações nos níveis de Leptina; afirmando que esses são os principais marcadores séricos de alterações no padrão de gordura corporal em equinos.

\section{CONCLUSÕES}

No grupo de éguas Crioulas de escore corporal normal $(\mathrm{GrN})$, foi observado maior ganho de peso no terço final da gestação, além de um incremento expressivo nas variáveis perímetro torácico, perímetro abdominal e um acúmulo regional de gordura subcutânea na base da cauda. $\mathrm{Na}$ comparação dos grupos ( $\mathrm{GrN}$ versus $\mathrm{GrO}$ ) nos meses de gestação, houve diferença nas varíaveis morfométricas, a excessão restringiu-se às variáveis perímetro abdominal e altura da crista do pescoço no $11^{\circ}$ mês de gestação. A Leptina foi a variável metabólica que melhor se correlacionou com o escore corporal, espessura de gordura subcutânea na base da cauda e espessura de gordura retroperitoneal.

Através dos métodos utilizados neste trabalho, é possivel a avaliação prática da morfometria das éguas da raça Crioula no terço final da gestação, possibilitando, de forma objetiva, a identificação de indivíduos obesos.

\section{AGRADECIMENTOS}

À CAPES e ao CNPq pelo apoio financeiro.

\section{REFERÊNCIAS}

\section{ANUÁRIO DA ASSOCIAÇÃO BRASILEIRA DE CRIADORES DE CAVALOS CRIOULOS. Dados quantitativos populacionais da raça Crioula. v.50, p.485, 2013.}

BENDER, E.S.C.; SAMPAIO, B.F.B.; NOGUEIRA, B.G. et al. Condição corporal e atividade reprodutiva de éguas. Arch. Zootec., v.63, p.55-67, 2014.
CAVINDER, C.A.; VOGELSANG, M.M.; GIBBS, P.G. et al. Endocrine Profile Comparisons of Fat Versus Moderately Conditioned Mares Following Parturition. J. Equine Vet. Sci., v.27, p.72-79, 2007.

CARROLL, C.L.; HUNTINGTON, P.J. Body condition scoring and weight estimation of horses. Equine Vet. J., v. 20, p. 41-45, 1988.

CARTER, R.A.; GEOR, R.J.; STANIAR, W.B. et al. Apparent adiposity assessed by standardised scoring systems and morphometric measurements in horses and ponies. Vet J., v.179, p.204-210, 2009.

CASTELLANO FILHO, D.S.; CORREA, J.O.A.; RAMOS, P.S. et al. Circunferência abdominal avaliada antes da $12^{\mathrm{a}}$ semana de gestação: correlação com níveis séricos de leptina. Rev Bras. Ginecol. Obstetric., v.34, p.268-73, 2012.

DUGDALE, A.H.A.; CURTIS, G.C.; CRIPPS, P.J. et al. Effect of season and body composition on appetite, body mass and body composition in ad libitum fed pony mares. Vet. J., v.109, p.379387, 2011.

FRADINHO M.J.; CORREIA, M.J.; GRÁCIO, V. et al. Effects of body condition and leptin on the reproductive performance of Lusitano mares on extensive systems. Theriogenology, v.81, p.1214-1222, 2014.

GENTRY, L.R.; THOMPSON, D.L.; GENTRY, G.T. et al. The relationship between body condition score and ultrasonic fat measurements in mares of high versus low body condition. $J$. Equine Vet. Sci., v.24, p.198-203, 2004.

HENNEKE,D.R.; POTTER,G.D.; KRIEDER, J.L. et al. Relationship between condition score, physical measurements and body fat percentage in mares. Equine Vet. J., v.15, p.371-372, 1983.

KEARNS, C.F.; MCKEEVER, K.H.; ROEGNER, V. et al. Adiponectin and leptin are related to fat mass in horses. Vet. J., v.172, p.460-465, 2006.

KNIGHT, K.; SUKALICH, S.; MINGIONE, M. et al. Effect of maternal obesity on fetal metabolism and growth: a pilot study. Am. J. Obstet. Gynecol., Supplement to December 2009. 
KOHNKE, J. Feeding and Nutrition: The Making of a Champion. Australia. Birubi Pacific, Pymble, 1992.163-166p.

LAWRENCE, L. M.; DI PIETRO, J.; PARRETT, D. et al. Changes in boby weight and condition of gestating mares. J. Equine Vet. Sci., v.12, p.355-358, 1992.

MANSO FILHO, H.C.; MANSO, H.E.C.C.; FERREIRA, L.M.C. et al. Percentagem de gordura de cavalos criados em região tropical. Acta Sci. Vet., v.37, p.239-243, 2009.

MARTINELLI, S.; BITTAR, R.E.; ZUGAIB, M. Proposta de nova curva de altura uterina para gestações entre a $20^{\mathrm{a}}$ e a $42^{\mathrm{a}}$ Semana. RBGO., v.23, p.235-241, 2001.

MEYER, H.; AHLSWEDE, L. The intra-uterine growth and body composition of foals and the nutrient requeriments of pregnant mares. Anim Res Dev., v.6, p.86- 111,1978.
PAZ, C.F.R.; PAGANELA, J.C.; DOS SANTOS, C.A. et al. Relação entre obesidade, insulina plasmática e posicionamento da falange distal em equinos da raça crioula. Arq. Bras. Med. Vet. Zootec., v.65, p.1699-1705, 2013.

SCHEIBE, K.M.; STREICH, W.J. Annual rhythm of body weight change in Przewalski horses (Equus ferus przewalskii). Biol. Rhythm. Res., v.34, p.383-395, 2003.

TAKAHIRO, A.; MITSUO, I. Hematological and biochemical profiles in peripartum mares and neonatal foals (Heavy Draft Horse), J. Equine Vet. Sci., v.32, p.170-176, 2011. 